\title{
The Economic Burden of Heart Failure
}

\author{
J. B. O'CONNELL, M.D. \\ Department of Internal Medicine, University Health Center, Wayne State University, Detroit, Michigan, USA
}

Summary: Heart failure, a major cause of morbidity and mortality among the elderly, is a serious public health problem. As the population ages and the prevalence of heart failure increases, expenditures related to the care of these patients will climb dramatically. As a result, the health care industry must develop strategies to contain this staggering economic burden. Strategies may include adopting approaches for preventing heart failure and implementing new treatment modalities with proven efficacy into large-scale clinical practice. Successful implementation of these strategies will require intensive physician and patient education and development of innovative approaches to fund support services.

Key words: heart failure, economic burden, aging population, angiotensin-converting enzyme inhibitors, beta blockers, hospitalization costs

\section{Introduction}

Heart failure is a major public health issue. It is highly prevalent among the elderly population, and its prevalence is projected to rise markedly over the next decade. ${ }^{1,2}$ Even with the commitment to excellence in health care that exists in the United States, resources and personnel are limited; the economic burden of managing heart failure is staggering. It is, therefore, imperative that the medical profession examines the impact of developing technology and new therapeutic modalities on heart failure management. Efforts must be made to develop novel strategies to reduce the burgeoning cost of care of these patients without compromising the effectiveness of that care. ${ }^{3.4}$

Address for reprints:

J.B. O'Connell, M.D.

Department of Internal Medicine

Wayne State University

UHC $2 \mathrm{E}$

1402 St. Antoine

Detroit, MI 48201, USA

\section{Prevalence and Prognosis of Heart Failure}

\section{Prevalence}

Heart failure is a clinical syndrome that has become more prevalent in recent years. In 1996, almost 4.8 million Americans were afflicted with congestive heart failure (CHF), and each year approximately 400,000 new cases of CHF were diagnosed. ${ }^{5}$ Disease prevalence is expected to reach 10 million cases in the U.S. alone by the year 2007.6 Enhanced public awareness and advances in the management of acute myocardial infarction, diabetes, hypertension, and heart failure have led to decreased early mortality rates from these disorders while increasing the incidence of heart failure. ${ }^{2}$ In 1979 , there were 377,000 hospital discharges of patients with primary heart failure; this number increased to 870,000 in 1996 , accounting for $2.8 \%$ of all hospital discharges and $22 \%$ of all discharges for cardiovascular disease in the U.S. In 1991, there were 2.3 million hospital discharges of patients with a primary or secondary diagnosis of heart failure, and examination of nonfederal hospital discharge records for that year indicated an average length of stay of 7.7 days for such patients. ${ }^{4}$

\section{Prognosis}

Mortality rates from $\mathrm{CHF}$ continue to be high, with a 6-year mortality rate secondary to heart failure of $84 \%$ in men and $77 \%$ in women. ${ }^{7}$ In 1996 , heart failure caused 43,837 deaths; women accounted for a larger proportion $(62 \%)$ than men $(38 \%) .{ }^{5}$ Following the development of systolic dysfunction, heart failure usually progresses unpredictably and symptoms worsen. Once cardiac muscle loss and fibrosis become irreversible, disease advance becomes inexorable and death inevitably follows (Fig. 1).

\section{Impact of Aging Population}

As the population ages, the incidence of heart failure and its resulting mortality will continue to increase. ${ }^{7}$ In 1940, only $7 \%$ of Americans were expected to live to the age of 90 years; by $1980,24 \%$ of Americans were expected to reach the age of 90; however, the long-awaited aging of the 75 million baby boomers born between 1947 and 1964 is still to come. The 


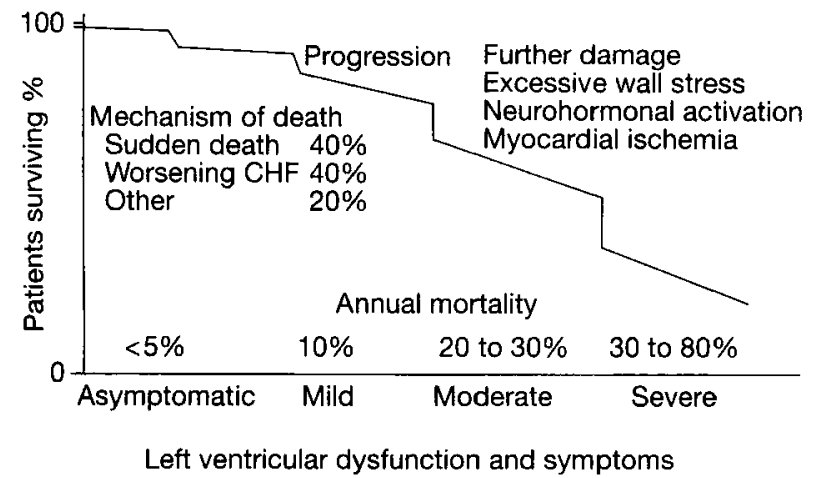

FIG. 1 Once left ventricular (LV) systolic dysfunction is present, it usually progresses, albeit not predictably. As LV dysfunction progresses and symptoms increase, the mortality rate increases and the process becomes inexorable. Myocyte loss and fibrosis become irreversible. An effective preventive measure must be introduced before onset or early in the course of progressive LV dysfunction. $\mathrm{CHF}=$ congestive heart failure. Reprinted from Ref. No. 13 with permission from Mosby, Inc

number of Americans over the age of 65 is expected to double in the next 30 years. ${ }^{8}$ The incidence of CHF approaches $1 \%$ in those over the age of 65 years, ${ }^{5}$ and has been reported at $4 \%$ in the 70- to 79-year age group. ${ }^{9}$

\section{Economic Impact of Heart Failure}

The costs related to heart failure management are difficult to assess. Hospital charges for heart failure management were approximately $\$ 10,000$ per discharge, based on a mean length of stay of 6.3 to 7.7 days. ${ }^{4}$ According to the Medicare program, Health Care Financing Administration (HCFA) expenditures for heart failure in 1991 were higher than those for cancer [based on the five most common diagnosis-related groups

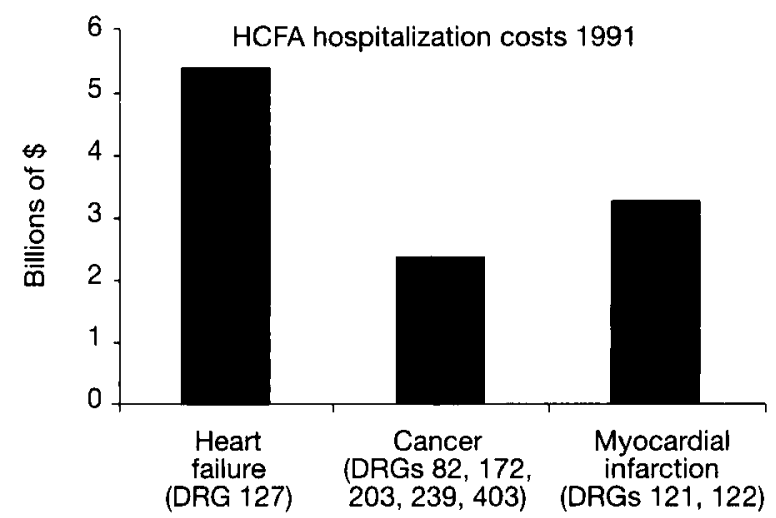

Fig. 2 Comparison of Health Care Financing Administration expenditures on heart failure compared with cancer and myocardial infarction according to the Medicare program. Reprinted from Ref. No. 4 with permission from Elsevier Science.
(DRGs) for cancer combined] and higher than those for myocardial infarction (based on two DRGs for myocardial infarction combined) (Fig. 2). ${ }^{4}$ Almost $75 \%$ of costs associated with a typical heart failure-related hospitalization (excluding hotel charges) accumulate within the first $48 \mathrm{~h}$. It is interesting that payer mix does not have a major impact on charges or length of stay, even when HMOs, indemnity insurance, and government programs were considered.

Heart failure-related readmission rates range from 15 to $30 \%$ at 90 days; data suggest that half of these readmissions could be prevented. ${ }^{10,11}$ Although approximately $70 \%$ of patients with heart failure are classified as New York Heart Association (NYHA) class I or II and do not experience recurrent hospitalizations, the total expenditure in 1991 for heart failure hospitalizations alone (federal hospitals excluded) was $\$ 23$ billion. ${ }^{4}$ However, in addition to hospitalization charges, outpatient expenses exceeded $\$ 4,000$ per patient per year. With an average of 3.4 outpatient visits per patient per year, total ambulatory costs exceeded $\$ 13$ billion. ${ }^{4}$ Transplantation costs $(\$ 250$ million) are a relatively small proportion of the total expenditure; a limited number of heart transplant procedures are performed each year. ${ }^{12}$

In summary, the annual expenditure on heart failure management, encompassing hospitalization costs (including inpatient care and pharmacy costs) and outpatient visits, for the 4.8 million patients in the U.S. approached $\$ 38$ billion in $1991 .{ }^{4} \mathrm{~A}$ more recent study of 29,000 patients with heart failure reported an average cost of almost $\$ 11,000$ per patient per hospitalization (Heart Failure BOI Analysis 1997, Merck \& Co., data on file). Thus, costs have not been reduced despite advances in medical treatment. Based on an increase in the number of patients with heart failure since 1990, the total cost for heart failure management in 1999 is estimated to approach $\$ 56$ billion. As the population ages and the number of patients with heart failure increases, the economic burden of managing these patients may become unmanageable.

\section{Strategies for Managing the Burden of Heart Failure}

\section{Economic-Based Targets}

Since hospitalization costs account for a major portion of expenses related to heart failure management, decreasing hospital length of stay may be desirable. However, economic gains realized by shortening hospital length of stay may potentially be compromised by increases in hospital readmission rates or emergency room visits. Efforts directed at decreasing hospital length of stay do not affect the majority of hospitalization costs ( $75 \%$ of non-hotel costs occur within the first $48 \mathrm{~h}$ ). Thus, it may be more cost effective to stabilize patients in the hospital, allowing for short increases in hospital length of stay, but reducing overall hospital readmission rates and number of emergency room visits. In Michigan, health care systems are encouraged to prevent frequent hospitalizations; Medicare DRG reimbursements for a rehospitalization with 15 days of discharge are not granted. 
TABLE I Strategies to prevent heart failure and its progression

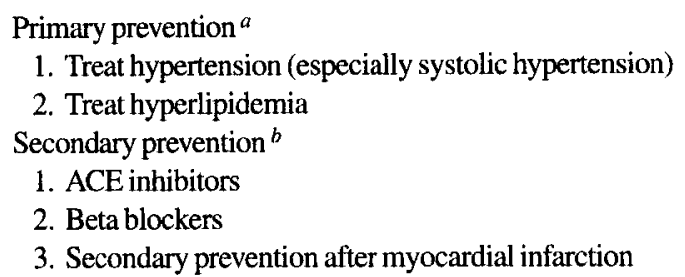
(a) Aspirin
(b) Beta blockers
(c) Antihyperlipidemic therapy
(d) Anticoagulation therapy
(e) Coronary revascularization (in appropriate patients)

Tertiary prevention ${ }^{c}$

1. ACE inhibitors

2. Beta blockers

3. Digoxin

4. Secondary prevention after myocardial infarction

5. Intensive home monitoring and intervention

${ }^{a}$ Before onset of left ventricular dysfunction or cardiac disease.

${ }^{b}$ After onset of left ventricular dysfunction or coronary artery disease, but before CHF.

${ }^{c}$ After onset of heart failure to delay progression and prevent clinical events.

Abbreviations: $\mathrm{ACE}=$ angiotensin-converting enzyme, $\mathrm{CHF}=\mathrm{con}-$ gestive heart failure.

Reprinted from Ref. No. 13 with permission from Mosby, Inc.

\section{Medical-Based Targets}

Health care professionals need to improve implementation of primary, secondary, and tertiary strategies (Table I) for preventing the onset and progression of heart failure. ${ }^{13}$ Nearly $75 \%$ of patients with heart failure have antecedent hypertension. ${ }^{5}$ The incidence of heart failure is higher than average in survivors of myocardial infarction; about $20 \%$ of these patients become disabled with heart failure within 6 years. ${ }^{5}$ The primary prevention strategy, introduced before the onset of left ventricular (LV) dysfunction, involves treatment of diabetes, hypertension, and hyperlipidemia; discontinuation of smoking; and prompt management of underlying cardiac disorders including coronary artery disease or valvular heart disease. Initiated after the onset of $L V$ dysfunction but before clinical heart failure, secondary prevention involves treatment with angiotensin-converting enzyme (ACE) inhibitors, beta blockers, aspirin, antihyperlipidemic agents, anticoagulation therapy, and coronary revascularization, if appropriate. After the onset of clinical heart failure, tertiary prevention/treatment involves pharmacologic therapy with ACE inhibitors, beta blockers, digoxin, and diuretics; prevention of recurrent myocardial infarction; and intensive home monitoring to delay disease progression and prevent clinical events. ${ }^{13}$

Use of ACE inhibitors: Results of the Studies of Left Ventricular Dysfunction (SOLVD), ${ }^{14}$ Veterans Administration Cooperative Vasodilator-Heart Failure Trial (V-HeFT II), ${ }^{15}$ and Cooperative North Scandinavian Enalapril Survival Study
(CONSENSUS) $)^{16}$ trials demonstrated that ACE inhibitors reduce disability, improve functional capacity, and prolong life among patients with heart failure. Furthermore, this drug class was well tolerated in more than $80 \%$ of study patients. ${ }^{14,15}$ Angiotensin-converting enzyme inhibitor treatment reduced hospital readmission rates; ACE-inhibitor therapy decreased the risk of 90- and 180-day rehospitalizations in patients with heart failure. ${ }^{17}$ However, reductions in morbidity and mortality associated with ACE-inhibitor and beta-blocker treatment have not yet translated into reduced mortality in national heart failure statistics. ${ }^{18,19}$

Underutilization of ACE inhibitors may contribute to the absence of the reduction in national heart failure morbidity and mortality. The overall use of ACE inhibitors in Medicare patients admitted to acute care hospitals with a principal diagnosis of heart failure ranges from 48 to $57 \% .^{20}$ Ideal candidates for $\mathrm{ACE}$ inhibitor therapy include patients with low ejection fraction (EF) $(<40 \%)$, normal renal function, and normal serum potassium. However, only $73 \%$ of patients most likely to benefit from and tolerate such therapy are prescribed ACE inhibitors at hospital discharge. ${ }^{20}$ Advanced age was associated with decreased prescription rates among ideal candidates; $78 \%$ of patients 65 to 74 years and $67 \%$ of those $\geq 85$ years were prescribed ACE inhibitors at hospital discharge. ${ }^{20}$ Physician specialty also affects prescribing practices. Cardiologists prescribe ACE inhibitors to their patients with CHF more often (46\%) compared with all other physicians $(22 \%) ;{ }^{21}$ cardiologists also tend to prescribe these agents earlier in the course of CHF treatment than do internists and family or general practitioners. ${ }^{22}$

Obtaining an objective assessment of LV systolic function is associated with ACE inhibitor use. Of hospitalized Medicare patients with CHF, $48 \%$ lacked documentation of $\mathrm{LV}$ function in the medical record. ${ }^{23}$ Patients with an objective assessment of LV function were prescribed ACE inhibitors more often at hospital discharge than patients without an LV assessment ( 56 vs. $48 \%, p=0.006$ ). In addition, when LV function was assessed at hospital admission, significantly more patients were prescribed ACE inhibitors at hospital discharge than patients without an assessment of $\mathrm{LV}$ function, even if $\mathrm{EF}$ was low ( 36 vs. $26 \%, \mathrm{p}=0.004$ ).

Appropriate ACE inhibitor dosing is also an important determinant of clinical outcome. The Assessment of Treatment with Lisinopril and Survival (ATLAS) trial compared the effects of low- and high-dose ACE inhibitors on the survival of patients with heart failure. ${ }^{24}$ Compared with low-dose lisinopril, treatment with high-dose lisinopril resulted in small reductions in both total mortality ( 42.5 vs. $44.9 \%, \mathrm{p}=0.128)$ and cardiovascular mortality (37.2 vs. $40.2 \%, p=0.073){ }^{25}$ However, treatment with high doses of the ACE inhibitor reduced heart failure-related hospitalizations by $24 \%$ compared with the low-dose therapy $(\mathrm{p}=0.003){ }^{25}$

In a retrospective outpatient chart audit evaluating guideline implementation in the management of $\mathrm{CHF}, 50 \%$ of 16,603 patients with $\mathrm{CHF}$ were prescribed an $\mathrm{ACE}$ inhibitor, but overall only $26 \%$ of patients received the recommended target dose. ${ }^{26}$ 
Improved timing and accuracy of heart failure diagnosis: It is recommended that all patients with heart failure undergo a complete diagnostic evaluation to (1) determine the type and severity of their cardiac dysfunction, (2) uncover correctable etiologic factors, (3) determine prognosis, and (4) guide treatment. ${ }^{27}$ Routine diagnostic studies for adult patients with heart failure include complete medical history; physical examination; exercise stress testing to assess functional capacity and symptomatic limitations; transthoracic echocardiography for specific assessment of ventricular mass, chamber size, systolic and diastolic function, and valvular abnormalities; and other noninvasive tests to detect ischemia and assess myocardial viability. ${ }^{8}$ These diagnostic tests are essential to evaluate patients with heart failure and to determine an underlying cause that can be appropriately treated by specific therapies; improvements in the definition and detection of heart failure classes are also needed. ${ }^{9.18}$

\section{Compliance-Based Targets}

Patients' failure to comply with physician instructions frequently contributes to disease-related complications. Patients are often noncompliant with prescribed medication regimens; $15 \%$ of hospital readmissions are related to medication noncompliance. ${ }^{10}$ The Merck Study defined compliance as refilling $80 \%$ of prescriptions on time and continuing prescriptions for a 1-year period; only $46 \%$ of patients with heart failure were compliant. Proprietary issues that affect patient compliance include regimen complexity, prescription size, side-effect profile, patient education, medication effectiveness, cost, and physician factors. It is interesting that DiMatteo et al. reported that the most important physician factor was physician global job satisfaction. Physicians who were happier in their work appeared to improve patient adherence. ${ }^{28}$

Only $10 \%$ of eligible patients with heart failure follow appropriate ACE inhibitor medication regimens when factors are combined for patient noncompliance and inaccurate medication dosing. Savings would be enormous if all eligible heart failure patients were prescribed the correct ACE inhibitor regimen and adhered to physicians' recommendations. Consider the following analysis: for 1,000 patients with heart failure taking enalapril at a cost of $\$ 540$ per person per year, the total 3 -year cost would be $\$ 1.6$ million. Approximately 350 hospitalizations would be prevented over these years ${ }^{14}$ and, at an average cost of $\$ 10,770$ per hospitalization, the savings would amount to $\$ 3.7$ million. The net savings (prevented hospitalization minus enalapril costs) would be $\$ 2$ million per 1,000 patients over 3 years. For the entire population of 4.78 million patients with heart failure in the U.S., the net 3-year savings would be $\$ 10$ billion.

Clinical trials, which contain the necessary infrastructure, ensure that a large percentage of patients receive medication prescriptions, maintain appropriate medication regimens, and require patient compliance. However, routine clinical practice lacks such an infrastructure. Managed care and discounted fee-for-service do not allow direct funding of support services such as follow-up visits, home visits, or education. Fee-forservice arrangements are limited primarily to physician encounters and hospitalizations. During a patient's hospitalization, physicians receive a daily fee. It is in the interest of the hospital, however, to discharge the patient as soon as possible; thus, a divergence in economic outlook is created. Although a huge financial benefit exists for managed care providers to ensure patient compliance, patient compliance issues are not properly addressed under the current system.

\section{Conclusion}

There are 4.78 million patients with heart failure in the United States, of whom 1.4 million are in NYHA class III or IV at any given time. More than $\$ 56$ billion is spent annually on the treatment and management of heart failure, $70 \%$ of which covers the hospitalization of patients. There is a need to develop innovative solutions to keep this growing population out of the hospital and to improve the overall management of the patients. Success in this endeavor will have a beneficial impact on our entire health care system.

\section{References}

1. Kannel WB, Ho K, Thom T: Changing epidemiological features of cardiac failure. Br Heart J 1994;72:S3-S9

2. Anonymous: Mortality from congestive heart failure-United States, 1980-1990. Morbidity and Mortality Weekly Report 1994; 43:77-81

3. Bodenheimer $\mathrm{T}$ : The American health care system-the movement for improved quality in health care. $N$ Engl J Med 1999;340: $488-492$

4. O'Connell JB, Bristow MR: Economic impact of heart failure in the United States: Time for a different approach. J Heart Lung Transplant 1994;13:S107-S112

5. American Heart Association: 1999 Heart and Stroke Statistical Update, Dallas, Tex.: American Heart Association, 1998

6. Rich MW: Epidemiology, pathophysiology, and etiology of congestive heart failure in older adults. J Am Geriatr Soc 1997;45: 968-974

7. Croft JB, Giles WH, Pollard RA, Keenan NL, Casper ML, Anda RF: Heart failure survival among older adults in the United States: A poor prognosis for an emerging epidemic in the Medicare population. Arch Intern Med 1999;159:505-510

8. Rich MW: Heart failure. Cardiol Clin 1999;17:123-135

9. McKinnon ME, McKee CM: Heart failure: The Cinderella of cardiology? Public Health 1996;1 10:351-355

10. Vinson JM, Rich MW, Sperry JC, Shah AS, McNamara T: Early readmission of elderly patients with congestive heart failure. $J$ Amer Geriatric Soc 1990;38:1290-1295

11. Ely JW, Burch RJ, Vinson DC: The information needs of family physicians: Case-specific clinical questions. J Fam Pract 1992;35: 265-269

12. United Network for Organ Sharing. U.S. Facts about Transplantation. 1998. Richmond, Va., United Network for Organ Sharing

13. Massie BM, Shah NB: Evolving trends in the epidemiologic factors of heart failure: Rationale for preventive strategies and comprehensive disease management. Am Heart J 1997;133:703-712

14. Effect of enalapril on survival in patients with reduced left ventricular ejection fractions and congestive heart failure. The SOLVD Investigators. N Engl J Med 1991;325:293-302 
15. Cohn JN, Johnson G, Ziesche S, Cobb F, Francis G, Tristani F, Smith R, Dunkman WB, Loeb H, Wong M, Bhat G, Goldman S, Fletcher RD, Doherty J, Hughes CV, Carson P, Cintron G, Shabetai $\mathrm{R}$, Haakenson C: A comparison of enalapril with hydralazine-isosorbide dinitrate in the treatment of chronic congestive heart failure. NEngl JMed 1991;325:303-310

16. The CONSENSUS Trial Study Group: Effects of enalapril on mortality in severe congestive heart failure. Results of the Cooperative North Scandinavian Enalapril Survival Study (CONSENSUS). The CONSENSUS Trial Study Group. N Engl J Med 1987;316: $1429-1435$

17. Miller LW, Merkle EJ, Jennsion SH: Outpatient use of dobutamine to support patients awaiting heart transplantation. Transplantation 1994;13:S126-S129

18. Ho KKL, Anderson KM, Kannel WB, Grossman W, Levy D: Survival after the onset of congestive heart failure in Framingham Heart Study subjects. Circulation 1993;88:107-115

19. McDermott MM, Feinglass J, Lee P, Mehta S, Schmitt B, Lefevre F, Puppala J, Gheorghiade M: Heart failure between 1986 and 1994: Temporal trends in drug-prescribing practices, hospital readmissions, and survival at an academic medical center. Am Heart $J$ 1997;134:901-909

20. The Large State Peer Review Organization Consortium: Heart failure treatment with angiotensin-converting enzyme inhibitors in hospitalized Medicare patients in 10 large states. The Large State Peer Review Organization Consortium. Arch Intern Med 1997;157: 1103-1108

21. Stafford RS, Saglam D, Blumenthal D: National patterns of angiotensin-converting enzyme inhibitor use in congestive heart failure. Arch Intern Med 1997;157:2460-2464
22. Rajfer SI: Perspective of the pharmaceutical industry on the development of new drugs for heart failure. J Am Coll Cardiol 1993;22: $198 \mathrm{~A}-200 \mathrm{~A}$

23. Ghali JK, Giles T, Gonzales M, Horswell R, Kumar S, Lejuene A, Livaudais GF, Sarkar IC: Patterns of physician use of angiotensin converting enzyme inhibitors in the inpatient treatment of congestive heart failure. J La State Med Soc 1997; 149:474-484

24. Packer M: Do angiotensin-converting enzyme inhibitors prolong life in patients with heart failure treated in clinical practice? (editorial). J Am Coll Cardiol 1996;28:1323-1327

25. Hobbs RE: Results of the ATLAS study. High or low doses of ACE inhibitors for heart failure? Cleve Clin J Med 1998;65:539-542

26. Sueta CA, Chowdhury M, Boccuzzi SJ, Smith SC Jr, Alexander CM, Londhe A, Lulla A, Simpson RJ Jr: Analysis of the degree of undertreatment of hyperlipidemia and congestive heart failure secondary to coronary artery disease. Am J Cardiol 1999;83: $1303-1307$

27. American College of Cardiology/American Heart Association Task Force on Practice Guidelines: Guidelines for the evaluation and management of heart failure. Report of the American College of Cardiology/American Heart Association Task Force on Practice Guidelines (Committee on Evaluation and Management of Heart Failure). J Am Coll Cardiol 1995;26:1376-1398

28. DiMatteo MR, Sherbourne CD, Hays RD, Ordway L, Kravitz RL, McGlynn EA, Kaplan S, Rogers WH: Physicians' characteristics influence patients' adherence to medical treatment: Results from the Medical Outcomes Study. Health Psychol 1993;12:93-102 